\title{
Análise de alternativas de tarifação e utilização de geradores aplicados em uma empresa do segmento de revestimentos cerâmicos
}

\author{
João Mota Neto* \\ Joice Maffioletti**
}

\begin{abstract}
RESUMO - O consumo de energia elétrica e todos os gastos referentes a essa necessidade são temas frequentes de estudos das mais diversas áreas do conhecimento. A tarifação da energia elétrica e suas classificações e contratos são um fator importante a ser analisando no momento de estimar custos fixos de produção. Assim as empresas devem analisar de forma eficaz a melhor opção de tarifação a ser aplicada para sua realidade, para evitar despesas indesejáveis com o consumo de energia elétrica na indústria. Neste contexto é abordado um estudo de caso comparando as opções de tarifação, e alternativas de geração de energia elétrica próprias.
\end{abstract}

Palavras-chave: Energia. Tarifação. Geração de energia.

\section{INTRODUÇÃO}

O histórico do consumo elétrico nacional tem demonstrado um aumento significativo nas últimas décadas, consequência da vasta disponibilidade de tecnologias de consumo tanto residenciais quanto industriais. Esta necessidade cada vez mais elevada de gerar e distribuir energia elétrica no país tem impulsionado os setores responsáveis em buscar um planejamento que auxilie de forma eficaz a manter literalmente o controle da situação. Uma das ações planejadas para conter o crescimento descontrolado do consumo por parte das indústrias, que representa $40 \%$ do consumo total nacional, foi a aplicação de multas para os consumidores que ultrapassassem a demanda contratada; e outra tão quanto relevante foi o reajuste do valor cobrado pela energia utilizada no horário de ponta.

Assim as empresas começaram a considerar o desligamento estratégico de determinadas cargas elétricas no período de maior valor de tarifação, visando contabilizar significativos aumentos nas faturas de energia. A legislação autoriza a aplicação de diferentes tipos de faturas. As concessionárias dispõem da estrutura horo-sazonal, caracterizada pela atribuição de tarifas diferenciadas de consumo de energia elétrica $(\mathrm{kWh})$ e de demanda de potência $(\mathrm{kW})$ de acordo com as horas de empregabilidade no dia e nos períodos do ano. A implantação de tarifa horosazonal constata que o perfil de comportamento do consumo ao longo do dia encontra-se vin-

\footnotetext{
* Mestre em engenharia mecânica pela UFRGS. É professor e pesquisador da Faculdade SATC. Endereço eletrônico: joao.neto@satc.edu.br.

** Acadêmica da $9^{a}$ fase de engenharia mecânica da Faculdade SATC. Endereço eletrônico: joice_maffioletti@ hotmail.com.
} 
culado aos hábitos do consumidor e às características próprias do mercado de cada região. As tarifas definidas são as chamadas de Tarifa Horo-Sazonal Verde e Tarifa Horo-Sazonal Azul.

Através de estudos, detectou-se que a utilização de geradores pode, em muitos casos, viabilizar este procedimento de suprimento de energia com valor mais atraente para essa faixa de horário. Essa aplicação de geradores independentes de energia elétrica situa-se como a mais cogitada opção de viabilizar um fornecimento alternativo, suprindo uma parte da energia utilizada no momento em que a tarifa é mais cara. Além disso, em épocas de racionamento, esta possibilidade pode evitar a sobretaxa no consumo de energia sem cortes na produção.

\section{TARIFAÇÃO DE ENERGIA ELÉTRICA}

$\mathrm{Na}$ comercialização de energia elétrica, a legislação brasileira permite que as concessionárias calculem as suas faturas de cobrança em função de diferentes fatores, tais como: consumo (kWh), demanda, fator de potência (SAUER, 2002).

A legislação autoriza ainda a aplicação de diferentes tipos de faturas como propriedades para faturamento das concessionárias. Utilizando-se dessa abertura, as concessionárias dispõem da estrutura horo-sazonal caracterizada pela atribuição de tarifas diferenciadas de consumo de energia elétrica $(\mathrm{kWh})$ e de demanda de potência $(\mathrm{kW})$ de acordo com as horas de empregabilidade no dia e nos períodos do ano. A estrutura tarifária horo-sazonal foi estabelecida apenas em 1988, com a publicação pelo DNAEE da Portaria no 33, em 11 de fevereiro de 1988, considerando a conveniência de imprimir melhor aproveitamento do sistema elétrico e consequentemente de minimizar as necessidades para ampliação de sua capacidade (AMARAL, 2006).

O enquadramento na tarifa Convencional exige um contrato específico com a concessionária no qual se pactua um único valor da demanda pretendida pelo consumidor (Demanda Contratada), independentemente da hora do dia ou período do ano. O enquadramento na tarifa Verde dos consumidores é opcional. Essa modalidade tarifária exige um contrato específico com a concessionária com a qual se pactua a demanda pretendida pelo consumidor, independentemente da hora do dia (ponta ou fora de ponta). Embora não seja explícita, a Resolução 456 permite a contratação de dois valores diferentes de demanda, um para o período seco e outro para o período úmido (TONIM, 2009, p. 46).

\section{ESTUDO DE CASO EM EMPRESA DE REVESTIMENTOS CERÂMICOS}

Localizada na Bahia, a empresa do segmento de revestimentos cerâmicos não se enquadra nas características para atuar como consumidor livre e nem receber qualquer incentivo 
na compra direta de energia elétrica da concessionária principal do estado, fatores que agregam um alto investimento com os gastos relacionados a energia elétrica. Os valores em reais de consumo por $\mathrm{MW} / \mathrm{h}$ no horário de ponta chegam a ser $70 \%$ maiores em comparação com as mesmas unidades localizadas no sul do Brasil, e o valor do $\mathrm{kW} / \mathrm{h}$ da demanda contratada nesta mesma faixa de horário é próximo a 190\% do valor pago pelo conjunto fabril da unidade do sul. As unidades localizadas na Bahia têm enorme problema com as constantes e prejudiciais paradas de energia elétrica ocorrentes na região. O prejuízo em reais no ano de 2009 chegou aproximadamente $\mathrm{R} \$ 930.000,00$ no total de 155 horas de produção parada.

Assim o estudo consiste em manter o processo de fabricação cerâmica durante o horário de ponta através de grupos geradores, considerando-se as possibilidades de se gerar energia em paralelo com a concessionária sem a alteração do contrato de fornecimento que atualmente usa a tarifação Horo-sazonal azul, e por outro lado, a geração total do consumo necessário para manter a produção no horário de ponta, desligando a concessionária e alterando o contrato, ambas de acordo com a avaliação da aplicação de diferentes tarifações.

Conforme informações da COELBA (Companhia de Eletricidade do Estado da Bahia), concessionária da unidade localizada na Bahia, o período considerado horário de ponta é compreendido entre $17 \mathrm{~h} 30 \mathrm{~min}$ às $20 \mathrm{~h} 30 \mathrm{~min}$. Dessa forma, o total de horas de funcionamento do grupo de gerador a ser aplicado no parque fabril é de 720 horas anuais, ponderando-se 3 horas por dia, 5 dias por semana. Segundo o contrato de fornecimento de energia com a concessionária, a demanda de potência instalada desse consumidor é de $2700 \mathrm{~kW}$. A situação atual da relação da unidade consumidora com a concessionária de energia é de Consumidor Grupo A4 (alta tensão) com aproveitamento da tarifa horo-sazonal azul - essa modalidade tarifária exige um contrato específico com a concessionária, com a qual se pactua tanto o valor da demanda pretendida pelo consumidor no horário de ponta quanto o valor pretendido nas horas fora de ponta.

\subsection{AVALIAÇÃO DAS TARIFAÇÕES APLICÁVEIS}

De forma a determinar o melhor modelo de tarifação a ser contratado na unidade de estudo, realizou-se uma comparação das opções disponíveis para avaliar os gastos em cada uma delas na conta de energia. A Tabela 1 refere-se a Tarifação Azul, a Tabela 2 a Tarifação Verde e a Tabela 3 a Tarifação Convencional. Os valores em MWh dos consumos no horário de ponta foram estabelecidos de acordo com a fatura de energia do mês de Abril de 2010 da unidade de estudo, esta é a fonte para os valores de Demanda Ativa e Contratada. 
TABELA 1 - ANÁLISE DA TARIFA HORO-SAZONAL AZUL

\begin{tabular}{cr|rr}
\hline Demanda (R\$/kW) & & Consumo (R\$/MW) & \\
\hline Ponta & F. Ponta & Ponta & F. Ponta \\
63,32184 & 17,8281 & 227,74 & 139,17 \\
\hline Demanda (kW) & & Consumo (MWh) & F. Ponta \\
Ponta & F. Ponta & Ponta & $1.457,82$ \\
\hline Custo Demanda (R\$) & 2700 & 145,96932 & F. Ponta \\
\hline Ponta & F. Ponta & Custo Consumo (R\$) & $202.884,81$ \\
\hline 165.315,59 & $48.135,92$ & Ponta & R $\$ 450.604,63$ \\
\hline
\end{tabular}

FONTE: Tarifa de Energia da Unidade em Estudo.

De acordo com a tabela 1 , podemos destacar a diferença entre os valores pagos em reais pelo kW nos períodos dentro e fora de ponta. O mesmo procedimento de análise é adotado na Tarifação Verde. Juntamente com a consideração desta modalidade, devido às características de contrato, a unidade deverá ser completamente desligada no horário de ponta. $\mathrm{Na}$ tabela 2 , considerou-se, a fim de avaliação, apenas o período seco, por ser o de pior caso quanto à disponibilidade de produção de energia elétrica da concessionária, tendo o maior preço do KW.

TABELA 2 - ANÁLISE DA TARIFA HORO-SAZONAL VERDE

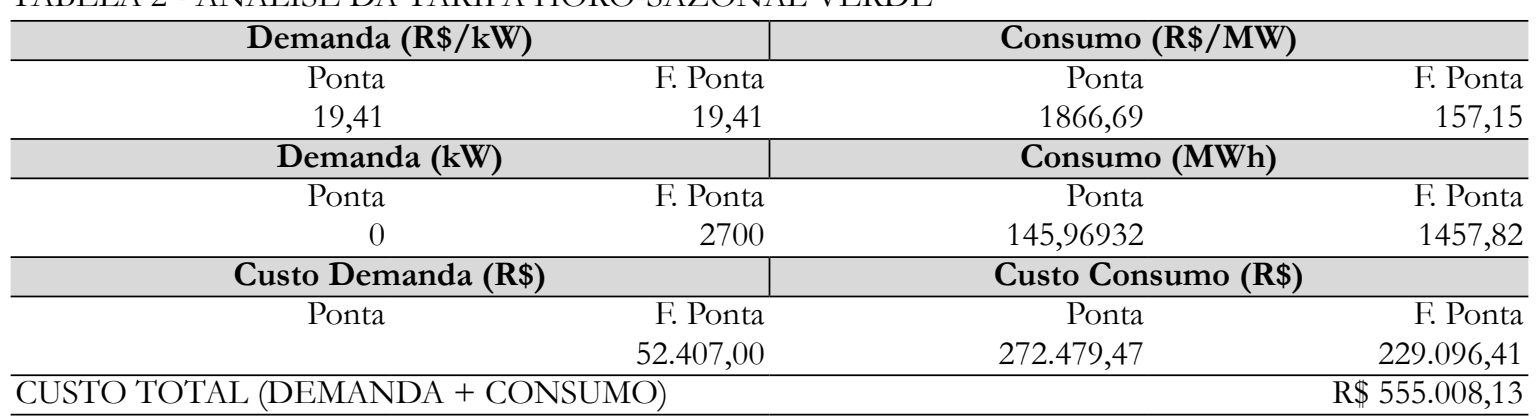

FONTE: Tabela de Tarifação da Concessionária Coelba 2010.

Por critérios de avaliação, destaca-se que se tratando de fornecimento único pela concessionária, o quadro de carga da empresa é mais bem atribuído à tarifação horo-sazonal azul devido às características de preço por kWh de consumo no horário de ponta. Porém, para garantir a eficiência desta escolha de tarifação, é necessária a instalação de um controlador de demanda potencial para evitar a ultrapassagem do valor de contrato e se tenha prejuízo com o consumo excedente.

\subsubsection{Custo de geração de energia elétrica e investimentos}

Para determinar o custo total da geração por hora e por kWh gerado foram analisadas duas características vitais: preço do combustível e preço de manutenção. Cerca de $90 \%$ do custo da energia gerada por grupos geradores devem ser debitados ao preço do combustível. 
Segundo dados dos sites dos fabricantes do grupo gerador, os valores referentes aos custos com manutenção apontam para uma média de US\$12,00 por MWh gerado para as máquinas acima de $500 \mathrm{~kW}$, podendo oscilar em torno da média (US\$12 14 ).

O custo total do investimento no projeto de geração de energia elétrica pode ser decomposto em grupo gerador, transformador elevador, acessórios para instalação elétrica e construção civil que totalizam em de $\mathrm{R} \$ 3.008 .500,00$. Os recursos aplicados nos investimentos a serem realizados possuem duas fontes distintas, a primeira será proveniente da redução na conta de energia elétrica oriunda da redução no contrato de demanda no horário de ponta e a utilização do grupo gerador para suprir a quantidade de energia que a empresa ainda necessita.

A segunda fonte tem origem nas ocasiões em que os grupos geradores funcionem no caso de falta de energia elétrica por parte da concessionária. Cada hora de parada de produção resulta num prejuízo de aproximadamente $\mathrm{R} \$ 1.200,00$ por linha de produção. A empresa possui 5 linhas de produção, o que resulta no prejuízo de $\mathrm{R} \$ 6.000,00$ por hora de fábrica parada.

\section{ANÁLISE E DISCUSSÃO DOS RESULTADOS}

A análise a ser realizada verifica quatro simulações diferentes de situações de contrato de energia com o intuito de estipular a opção que se torna mais atraente financeiramente para o usuário. Os gráficos analisados mostram os investimentos marcados com parênteses e os meses analisados em questão até o aparecimento dos lucros.

A primeira situação (Caso A.1) a ser avaliado de acordo com investimentos e retornos apresenta as condições de continuidade de serviço da tarifação azul com redução do valor total de demanda contratado no horário de ponta e a instalação de um grupo gerador de $2500 \mathrm{~kW}$.

A segunda análise (Caso A.2) apresenta a mesma característica base do primeiro caso, somente com o acréscimo de um grupo gerador de $1000 \mathrm{~kW}$, a fim de suprir toda a demanda da fábrica na ocasião de falta de energia. Isso possibilita que os valores financeiros referentes à parada de produção possam ser contabilizados. O valor de TMA (Taxa de mínima atratividade) aplicado é de $12 \%$ de acordo com dados fornecidos pelo Departamento Financeiro da Empresa. Segundo a análise obtêm-se os seguintes valores de payback mostrados no gráfico 1.

Com análise do VAUE, sabe-se exatamente quanto cada caso pode render por ano durante o ciclo de vida útil do projeto uniformemente. No primeiro caso avaliado o investimento renderá $\mathrm{R} \$ 429.423,96$ e no segundo caso o rendimento é de $\mathrm{R} \$ 831.488,55$ por ano.

As duas outras situações analisadas (Caso B.1 e B.2) possuem a característica de troca da tarifação vigente para Tarifa Horo-sazonal Verde, sendo que nesta situação se torna necessária a instalação dos dois grupos geradores pelo fato de terem que suprir toda a unidade 
consumidora.

GRÁFICO 1 - PAYBACK TARIFAÇÃO AZUL

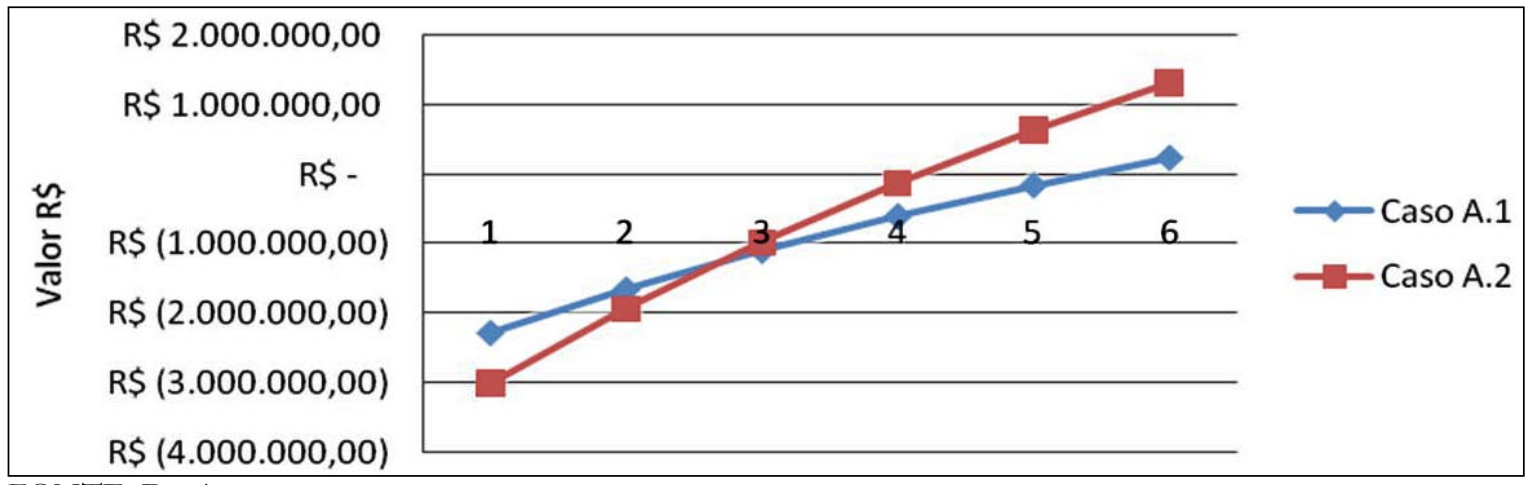

FONTE: Do Autor.

GRÁFICO 2 - PAYBACK TARIFAÇÃO VERDE

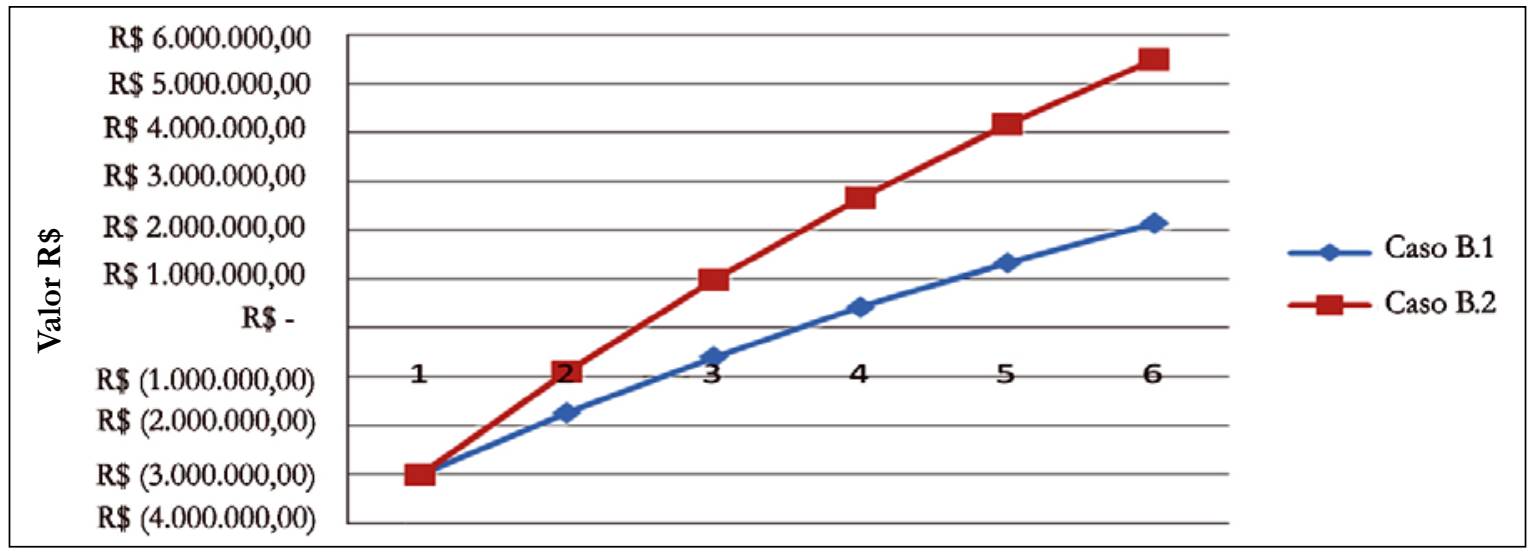

FONTE: Do Autor.

Deste modo a análise do caso B.1 foi contabilizada apenas com os ganhos na redução da conta de energia elétrica, e o caso B.2 além da redução na conta de energia elétrica se adiciona os valores dos ganhos referentes ao suprimento de energia na ocasião de falta pelo abastecimento principal. Segundo a análise, obtêm-se os valores de payback mostrados no Gráfico 2.

Com análise do VAUE, sabe-se exatamente quanto cada caso pode render por ano durante o ciclo de vida útil do projeto uniformemente. No primeiro caso referente a tarifação verde o investimento renderá $\mathrm{R} \$ 1.032 .755,61$ e no segundo caso o rendimento é de $\mathrm{R} \$$ 1.961.935,61 por ano.

As características elétricas da planta de uma empresa são de extrema importância devido à questão do consumo de energia elétrica ser um dos gastos mais relevantes. O primeiro passo é considerar as regulamentações que tentam de todas as formas evitar o desperdício por parte do consumidor final e cobrar fielmente todas as ações não se apresentarem de acordo com as suas exigências de serviço. Deve-se avaliar o melhor caminho para enquadrar no sistema 
de tarifação visa-se garantir os gastos reconhecidos serão apenas aqueles que realmente forem diretamente aproveitados.

\section{CONCLUSÃO}

De acordo com os dados e gráficos analisados, verifica-se a melhor opção vinculada ao consumo de energia elétrica na empresa do segmento de revestimento cerâmicos localizada na Bahia, sendo o grupo de geradores, com capacidade total de suprimento seria a opção de Tarifação Verde. Esta alternativa é atraente atendendo a ideia de que os geradores podem vir a não entrar em funcionamento quando lhes forem cabível, sendo assim a fábrica pode ser diretamente abastecida pela concessionária sem que maiores acréscimos e multas sejam acrescidas na conta de energia. Isso é consentido pela propriedade da Tarifação Verde de ter o mesmo valor em kW de demanda contratada no horário de ponta e no horário fora de ponta.

\section{REFERÊNCIAS}

AMARAL, D. F. Gerenciamento de energia elétrica. 61 f. Monografia (Graduação) - Departamento de Engenharia de Controle e Automação, Universidade Federal de Ouro Preto - Ufop, Ouro Preto, 2006.

SAUER, I. L. Energia elétrica no Brasil contemporâneo: a reestruturação do setor, questões e alternativas. In: BRANCO, A. M. (Org.). Política energética e crise de desenvolvimento: a antivisão de Catullo Branco. São Paulo: Paz e Terra, 2002.

TONIM, G. A gestão de energia elétrica na industria. 128 f. Dissertação (Mestrado) - Curso de Engenharia em Sistemas de Potência, Universidade de São Paulo, São Paulo, 2009. 
